\title{
Correlates of well-being among Canadians with mood and/or anxiety disorders
}

\section{H. Orpana, PhD (1,2); J. Vachon, MSc (1); C. Pearson, MA (1); K. Elliott, PhD (2); M. Smith, MSc (3); B. Branchard (1)}

This article has been peer reviewed.

\begin{abstract}
Introduction: Our objective was to examine variables associated with well-being as measured by high self-rated mental health (SRMH) and life satisfaction (LS), among Canadian adults (aged $18+$ ) living with a mood and/or an anxiety disorder.

Methods: We used nationally representative data from the 2014 Survey on Living with Chronic Diseases in Canada-Mood and Anxiety Disorders Component (SLCDC-MA) to describe the association between well-being and self-management behaviours (physical activity, sleep and meditation) as well as perceived stress, coping and social support. We used multivariate logistic regression to model the relationship between these factors and measures of well-being.
\end{abstract}

Results: Approximately one in three individuals with mood and/or anxiety disorders reported high SRMH. The logistic regression models demonstrated that several characteristics such as being older, and reporting higher self-rated general health, fewer functional limitations, lower levels of perceived life stress, higher levels of perceived coping and higher levels of perceived social support were associated with higher levels of wellbeing. Self-management behaviours (including starting physical activity, meditation, adopting good sleep habits and attaining a certain number of hours of nightly sleep) were not significantly associated with measures of well-being in our multivariate model.

Conclusion: Canadian adults with mood and/or anxiety disorders who reported lower levels of perceived stress and higher levels of social support and coping were more likely to report high levels of well-being. This study contributes evidence from a representative population-based sample indicating well-being is achievable, even in the presence of a mood and/or an anxiety disorder.

Keywords: mood disorders, anxiety disorders, well-being, self-rated mental health, life satisfaction, adults, Canada

\section{Introduction}

Canada's mental health strategy, Changing Directions, Changing Lives, encourages a shift in focus from pathology and symptoms in people experiencing a mental disorder to the concept of recovery, that is, "living a satisfying, hopeful and contributing life" in the presence of mental health problems. ${ }^{1}$ Well-being is a positive state that is often defined in terms of hedonic, or emotional, well-being and eudemonic, or functional, well-being. ${ }^{2}$ Hedonic wellbeing often includes the presence of positive emotions and life satisfaction, while eudemonic well-being includes concepts such as self-actualization and finding meaning in life.

Both the Public Health Agency of Canada (PHAC) and the World Health Organization (WHO) approach mental health from a well-being perspective. PHAC defines mental health as "the capacity of each and all
Highlights

- One in three Canadians living with a mood and/or an anxiety disorder report very good or excellent selfrated mental health. The sample reported a relatively high level of life satisfaction. Well-being was lowest among those with both a mood and an anxiety disorder.

- Perceived stress, coping and social support were significantly associated with well-being. We observed no significant associations between selfmanagement behaviours and wellbeing.

- High levels of well-being are possible while living with a mood and/or an anxiety disorder.

of us to feel, think, and act in ways that enhance our ability to enjoy life and deal with the challenges we face. It is a positive sense of emotional and spiritual wellbeing that respects the importance of culture, equity, social justice, interconnections and personal dignity." ${ }^{3}$ This definition is similar to that of the World Health Organization, where "mental health is a state of well-being in which an individual realizes his or her own abilities, can cope with the normal stresses of life, can work productively and is able to make a contribution to his or her community." 4

The concept of quality of life (QOL) is related to, but distinct from well-being. According to the WHO, QOL refers to “individuals' perception of their position in life in the context of the culture and value systems in which they live and in relation to their goals, expectations,

\section{Author references:}

1. Public Health Agency of Canada, Ottawa, Ontario, Canada

2. School of Psychology, University of Ottawa, Ottawa, Ontario, Canada

3. Manitoba Centre for Health Policy, Faculty of Health Sciences, University of Manitoba, Winnipeg, Manitoba, Canada

Correspondence: Heather Orpana, Science Integration Division, Social Determinants and Science Integration Directorate, Health Promotion and Chronic Disease Prevention Branch, Public Health Agency of Canada, 785 Carling Avenue, Ottawa, ON K1A 0K9; Tel: 613-878-5011; Fax: 613-960-0944, Email: heather.orpana@phac-aspc.gc.ca 
standards and concerns." ${ }^{5}$ Many measures of quality of life include a subjective evaluation of life satisfaction (LS), either overall or with regard to specific domains.

In people living with a mood disorder, research has shown that well-being is associated with higher levels of overall functioning, ${ }^{6}$ and a number of lifestyle interventions have shown promise for enhancing well-being. ${ }^{7}$ However, most studies examining well-being among people living with a mood and/or an anxiety disorder are based on small, clinical samples and are not representative of the Canadian population. The purpose of this study is to examine factors associated with well-being, as measured by high selfrated mental health (SRMH) and satisfaction with life in general, among a representative sample of Canadians living with a mood and/or an anxiety disorder from the 2014 Survey on Living with Chronic Diseases in Canada (SLCDC). These factors include several self-management behaviours as well as perceived stress, coping and social support.

\section{Self-management behaviours for mood and/or anxiety disorders}

A number of behaviours are associated with a reduction of symptoms and better clinical outcomes among people living with mood and/or anxiety disorders. In our study, "self-management behaviours" refer to starting physical activity or meditation to manage one's disorder, adopting good sleep habits as well as attaining recommended amounts of sleep as measured by usual hours of sleep per night. These behaviours may be initiated by the individual, or suggested by a health care professional as part of a holistic approach to treatment. Each of these is described in relation to well-being below.

\section{Physical activity}

A range of behaviours that contribute to well-being may be adopted by people living with a mood and/or an anxiety disorder of their own accord, or at the suggestion of a health care professional as part of a clinical approach to care. Although physical activity is fairly well established in the literature for reducing symptoms in people experiencing mood disorders, ${ }^{8}$ there is also a growing body of evidence that it may improve well-being in people experiencing major depression and/or depressive symptoms..$^{8-10}$ For example, Galper et al. ${ }^{10}$ found a positive graded dose-response relationship between cardiorespiratory fitness and estimated mean general well-being, as well as a significant relation between the amount of physical activity and estimated general well-being scores.

The relationship between anxiety disorders and physical activity has been less frequently studied, and responses to exercise appear to vary by type of anxiety disorder. ${ }^{8,11}$ Nevertheless, there is some preliminary evidence that physical activity may be associated with an increase in well-being among people experiencing certain types of anxiety disorders, including post-traumatic stress disorder, generalized anxiety disorder, social anxiety disorder and obsessive compulsive disorder. ${ }^{12}$

\section{Sleep}

Sleep dysfunction is associated with both mood and anxiety disorders. ${ }^{13}$ Sleep quantity and quality among people living with mood and/or anxiety disorders are also associated with measures of well-being. For example, Hamilton et al. ${ }^{14}$ found that respondents living with major depressive disorder (MDD) who slept from 6 to 8.5 hours a night had higher psychological well-being as measured by Ryff's six dimensions of psychological well-being ${ }^{15}$ than those sleeping either more or less. Peth et al. ${ }^{16}$ found that participants diagnosed with MDD who were given the opportunity to nap during the day reported an increase in their subjective well-being, as compared to those who were kept awake with controlled activity during the same period.

\section{Meditation}

The use of meditation, particularly "mindfulness" meditation, in the treatment of mood and anxiety disorders has shown promising results in many treatment studies. ${ }^{17}$ Other types of meditation, such as "kindness-based meditation," have also shown promise, though with inconsistent effects on the well-being of participants experiencing a mood disorder. ${ }^{18}$ In one qualitative study examining individual coping strategies, many participants diagnosed with bipolar disorder (a mood disorder) reported using meditation as a means to self-manage the negative experiences of their disorder. ${ }^{19}$

\section{Stress, coping and social support}

Stress, coping and social support each have a well-documented relationship with well-being. Prolonged exposure to stressors can increase the risk of developing mental disorders as well as physical health problems, ${ }^{20,21}$ and there is an inverse relationship between perceived stress and well-being. ${ }^{22}$ Coping refers to the set of cognitive and behavioural strategies used by an individual to manage the demands of stressful situations, by solving problems or regulating emotions. ${ }^{23}$ Interventions that enhance positive coping skills have been associated with higher levels of wellbeing. ${ }^{24}$ Social support is consistently associated with well-being among people experiencing a mood and/or an anxiety disorder. For example, Kuehner and Buerger $^{25}$ found that the presence of an intimate partner was associated with increased quality of life ratings in the psychological and social relationship domains of subjective quality of life among participants experiencing unipolar depression. Panayiotou and Karekla ${ }^{26}$ found that among participants with a diagnosis of either generalized anxiety disorder, social anxiety disorder or panic disorder, higher perceived social support was predictive of higher psychological quality of life.

Although the evidence associating these factors with well-being in people living with mood and/or anxiety disorders is growing, there is still a clear need for more research to understand correlates of well-being in this population. Most studies to date examine these relationships in small convenience samples and clinical studies. Research about people living with mental disorders often focusses on negative outcomes (distress and dysfunction) even though well-being is recognized as an important and achievable outcome for people living with mental disorders. ${ }^{1}$ Our study will therefore add to the literature by describing well-being in a representative sample of Canadians living with a mood and/or an anxiety disorder, and by examining the association of self-management behaviours and stress, coping and social support factors with self-rated mental health (SRMH) and life satisfaction (LS) in this sample. Based on the literature available to date, we predicted that each of the self-management behaviours, as well as lower stress and higher social support and coping, would be positively associated with higher SRMH and LS. 


\section{Methods}

We analyzed data from the 2014 Survey on Living with Chronic Diseases in Canada-Mood and Anxiety Disorders Component (SLCDC-MA). The survey population consists of 3361 individuals aged 18 years and older who reported in the 2013 Canadian Community Health Survey that they have been diagnosed with mood and/or anxiety disorders by a health professional. The methodology of the data collection and the sample of SLCDC-MA are described in the methodological paper that is included in this issue of Health Promotion and Chronic Disease Prevention in Canada. ${ }^{27}$

\section{Well-being}

We used two measures of well-being in this study: SRMH and LS. SRMH is an individual's global self-assessment of their mental health. We considered those who self-rated their mental health as being "excellent" or "very good" to have high SRMH, and those who reported it as "good," "fair" or "poor" to have low SRMH. Dichotomizing the variable in this manner creates a group that is consistent with the way this indicator is reported by Statistics Canada and PHAC..$^{28,29}$

Life satisfaction is a global assessment, evaluation or judgment of satisfaction with one's life based on an individual's own criteria. ${ }^{30}$ Consistent with Organisation for Economic Co-operation and Development guidelines for measuring subjective wellbeing, participants were asked "Using a scale of 0 to 10 , where 0 means 'very dissatisfied' and 10 means 'very satisfied,' how do you feel about your life as a whole right now?" Analysis of the LS data showed that responses were skewed and did not follow a normal distribution. Therefore, we did not use those responses as a continuous variable for analysis. Instead, we dichotomized the scale into two categories using a median split: high level of LS (with scores higher than or equal to 8), and low level of LS (with scores lower than 8). Other cut-offs for LS have not been widely used, and the choice of a median split maximizes the power to detect differences between two equal groups. Because this cut-off is based on the underlying distribution of scores, reporting prevalences are not meaningful; however, group comparisons of prevalences are valid.

\section{Health and functioning}

We evaluated the self-perceived general health of the participants using a single question. The response categories were "excellent," "very good," "good," “fair” and "poor."

We assessed functional limitations through a set of questions asking respondents how much their mood and/or anxiety disorder limited them in seven different areas in the past 12 months: recreation, leisure or hobbies; exercise or playing sports; social activities with family or friends; household chores; shopping and running errands; travelling and vacations; and bathing or dressing. Respondents were categorized into three groups: those reporting no or only a little functional limitation, those reporting a lot of limitations in one or two areas and those reporting a lot of limitations in three or more areas.

\section{Behaviours used to self-manage mood and/or anxiety disorders (physical activity, sleep and meditation)}

We identified exercise behaviours using combined responses to several questions. Respondents were asked if they started exercising in order to manage their mood and/or anxiety disorder, whether they still did exercise and how often they exercised. Categories of exercise behaviour included (1) started exercising because of diagnosis to manage condition and continued to do so every day of the week; (2) started exercising and continued 4 to 6 times a week; (3) started exercising and continued 2 to 3 times a week or less; (4) started exercising after diagnosis but stopped; and (5) never started exercising. We excluded participants who reported that they never started exercising because they already were exercising for other reasons from analyses examining physical activity $(\mathrm{n}=282)$.

We created two sleep habit variables based on responses to questions about sleep. Respondents were asked if they adopted good sleep habits (e.g. keeping a regular sleep schedule) to manage their mood and/or anxiety disorder ("yes" or "no") and how long they usually spend sleeping each night (we grouped responses into "less than 6 hours," "6 hours to less than 9 hours" or "9 hours and more").
Finally, respondents reported whether they used meditation to help manage their condition ("yes" or "no").

\section{Stress, coping and social support}

We measured perceived stress using the following question: "Thinking about the amount of stress in your life, would you say that most days are...?" Response categories were: "not at all stressful," "not very stressful," "a bit stressful," "quite a bit stressful" and "extremely stressful." The survey asked two questions that addressed ability to handle unexpected and difficult problems and day-to-day demands, which we used to measure coping. We considered coping ability to be high among those who had a score of at least 8 on the sum of the two coping questions.

Social support is the resources provided by other people to enhance an individual's well-being. It can include both tangible support, e.g. assistance with activities and physical resources, and intangible support, e.g. provision of information, affection or emotional assistance. ${ }^{31}$ Ten items from the Social Provisions Scale (SPS) ${ }^{32}$ were included on the SLCDC-MA, and respondents answered to what degree they agreed with each statement (e.g. "There are people who I can depend on for help if I really need it."). The SPS measures the concepts of reliable alliance, social integration, guidance and attachment. Participants whose mean score on the SPS was 3 or above (corresponding to an average response of "agree" or "strongly agree") were classified as having a high level of social support.

\section{Analysis}

In this study, we used descriptive data analysis to describe the well-being of individuals with mood and/or anxiety disorders. We examined the prevalence of high well-being by sociodemographic group, type of disorder, health and functioning, behaviours used to manage mood and/or anxiety disorders and stress, coping and social support variables. We also examined sex-stratified prevalences to identify possible effect modification. We performed logistic regression analysis in order to look at the associations between well-being and a) sociodemographic factors; b) health and functioning; c) selfmanagement behaviours; and d) stress, coping and social support. We built a series of hierarchical models, adding 
sequential blocks of variables as described above. We performed all analyses using SAS Enterprise Guide version 5.1 (SAS Institute, Cary, NC, USA). We calculated variance using balance repeated replicate weights in the PROC SURVEY suite of procedures, with the weights provided by Statistics Canada.

\section{Results}

Approximately one in three respondents reported high SRMH (31.4\%). Among those diagnosed with both mood and anxiety disorders, a significantly lower proportion reported high LS or high SRMH than those with only an anxiety disorder or only a mood disorder (Figure 1). Mean LS ratings were significantly higher for those with anxiety only $(7.49,95 \% \mathrm{CI}$ : 7.28-7.70) as compared to those with a mood disorder only (mean 7.01, 95\% CI: 6.84-7.18). Those with either a mood or an anxiety disorder only had significantly higher LS ratings than those with both disorders (mean 6.52, 95\% CI: 6.30-6.74).

\section{Bivariate analyses}

\section{Sociodemographic factors}

In bivariate analyses (Table 1), a higher proportion of individuals aged 65 and older reported high SRMH (39.5\%) in comparison to those aged 35 to 49 years $(26.3 \%)$. A higher proportion of those who were married or living common-law reported high LS $(52.7 \%)$ as compared to those who were single or never married (38.6\%) or widowed, divorced or separated $(36.8 \%)$. No significant differences in the level of well-being were observed by sex, education level, immigrant status or urban/rural residence.

\section{Health and functioning}

The proportion of respondents reporting high SRMH and high LS increased with higher levels of self-reported general health. A significantly higher proportion of individuals who reported no or only a little functional limitation had higher LS or SRMH than those with 1 to 2 limitations or 3 or more limitations. Those with 1 to 2 limitations had higher levels of well-being than those with 3 or more limitations.

\section{Self-management behaviours}

Respondents who reported sleeping from 6 to less than 9 hours per night had a significantly higher prevalence of high SRMH and high LS than those who slept less than 6 hours. There were no significant

FIGURE 1

Proportion of Canadians aged 18 years and older with a mood and/or an anxiety disorder reporting high self-rated mental health or life satisfaction, SLCDC-MA 2014

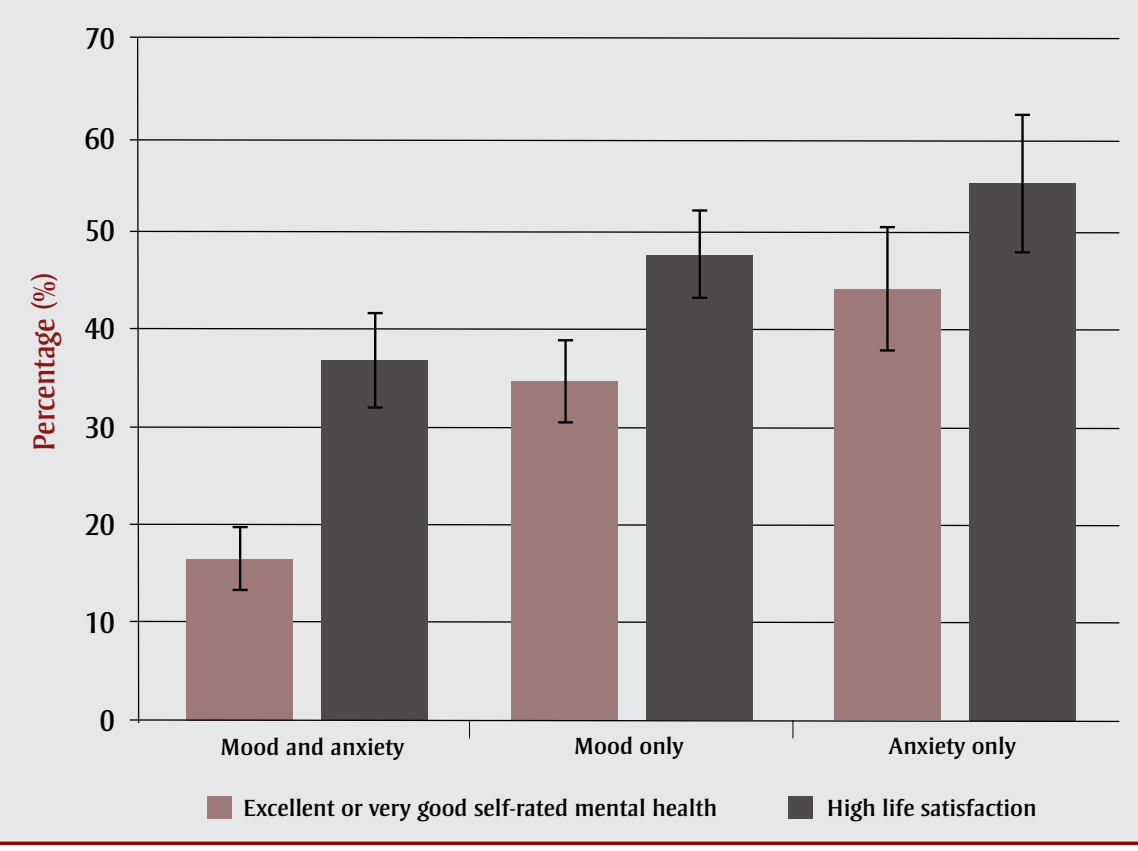

Abbreviation: SLCDC-MA, Survey on Living with Chronic Diseases in Canada-Mood and Anxiety Disorders Component.

Note: Error bars represent 95\% confidence intervals. differences between those who reported starting meditation, or starting or continuing an exercise routine or adopting good sleep habits.

\section{Stress, coping and social support}

The prevalence of high SRMH and of high LS increased with decreasing reported life stress (e.g. $20.0 \%$ of those reporting life as "quite a bit or extremely stressful" reported high SRMH, vs. $65.3 \%$ of those reporting life as "not at all stressful"). Better coping was associated with a higher prevalence of high SRMH and high LS compared to those who reported lower levels of coping $(59.5 \%$ vs. $21.8 \%$ for SRMH and $61.9 \%$ vs. $40.9 \%$ for LS for those with high vs. low coping, respectively). Similarly, higher levels of wellbeing were found among those with high perceived social support versus those with low perceived social support $(35.5 \%$ vs. $14.3 \%$ for SRMH and $51.8 \%$ vs. $22.8 \%$ for LS, respectively).

We examined sex-stratified prevalences (data not shown), and there was no evidence for important differences in the pattern of associations between men and women.

\section{Logistic regression}

The results of hierarchical logistic regression models are presented in Table 2 (SRMH) and Table 3 (LS).

\section{Self-rated mental health}

In the initial model including only sociodemographic variables (SRMH Model 1), only age and income were significantly associated with high SRMH (Table 2). Respondents aged 65 and older were almost twice as likely to report high SRMH as those aged 35 to 49 years. The odds of reporting high SRMH increased with increasing income. Marital status, sex, education, immigrant status and urban/ rural status were not significant predictors of high SRMH.

The likelihood of reporting high SRMH was significantly related to health and functioning variables added in Model 2 . Notably, those reporting excellent selfrated health were almost 13 times as likely to also report high SRMH, and those in very good health were 4 times as likely. Respondents reporting having no or 1 to 2 functional limitations were more likely to report high SRMH than those reporting 
TABLE 1

Percentage of respondents with high self-rated mental health or high life satisfaction by sociodemographic, health and functioning, self-management and stress, coping and social support characteristics, Canada, 2014 SLCDC-MA

\begin{tabular}{|c|c|c|}
\hline \multirow[t]{2}{*}{ Characteristics } & Self-rated mental health & Life satisfaction \\
\hline & $\begin{array}{l}\text { High level } \\
\%(95 \% \mathrm{CI})\end{array}$ & $\begin{array}{l}\text { High level } \\
\%(95 \% \mathrm{Cl})\end{array}$ \\
\hline \multicolumn{3}{|l|}{ Sex } \\
\hline Males & $29.9(24.9-34.8)$ & $43.1(37.4-48.7)$ \\
\hline Females & $32.2(29.1-35.4)$ & $48.0(44.4-51.6)$ \\
\hline \multicolumn{3}{|l|}{ Age } \\
\hline $18-34$ & $31.2(25.2-37.1)$ & $49.4(42.8-55.9)$ \\
\hline $35-49$ & $26.3(21.1-31.5)$ & $43.6(37.0-50.1)$ \\
\hline $50-64$ & $32.2(27.8-36.6)$ & $43.3(38.1-48.5)$ \\
\hline $65+$ & $39.5(34.4-44.6)$ & $51.5(46.1-56.9)$ \\
\hline \multicolumn{3}{|l|}{ Marital Status } \\
\hline Single/never married & $27.2(22.2-32.3)$ & $38.6(32.9-44.4)$ \\
\hline Widowed/divorced/separated & $27.8(22.8-32.7)$ & $36.8(31.0-42.5)$ \\
\hline Married/living common-law & $34.4(30.4-38.4)$ & $52.7(48.2-57.2)$ \\
\hline \multicolumn{3}{|l|}{ Highest education level } \\
\hline Less than secondary school graduation & $31.1(23.2-39.0)$ & $43.2(34.0-52.4)$ \\
\hline Secondary school graduation & $30.3(24.0-36.5)$ & $43.3(36.3-50.2)$ \\
\hline $\begin{array}{l}\text { Some post-secondary + post-secondary } \\
\text { graduation }\end{array}$ & $31.4(28.3-34.6)$ & $47.2(43.5-50.8)$ \\
\hline \multicolumn{3}{|l|}{ Household income quintile } \\
\hline Q1 (lowest quintile) & $23.5(19.1-27.9)$ & $33.9(28.2-39.5)$ \\
\hline Q2 & $31.0(25.2-36.8)$ & $37.6(31.2-44.0)$ \\
\hline Q3 & $32.8(26.4-39.2)$ & $47.0(39.9-54.2)$ \\
\hline Q4 & $32.4(26.2-38.6)$ & $53.9(47.1-60.8)$ \\
\hline Q5 (highest quintile) & $39.2(32.3-46.0)$ & $61.6(54.0-69.2)$ \\
\hline \multicolumn{3}{|l|}{ Immigrant } \\
\hline Yes & $30.0(20.9-39.1)$ & $46.4(35.7-57.2)$ \\
\hline No & $31.6(28.8-34.4)$ & $46.2(43.0-49.4)$ \\
\hline \multicolumn{3}{|l|}{ Urban and rural status } \\
\hline Urban & $30.0(26.9-33.1)$ & $44.7(41.2-48.2)$ \\
\hline Rural & $37.7(32.5-42.9)$ & $53.1(48.2-58.0)$ \\
\hline \multicolumn{3}{|l|}{ Self-rated health } \\
\hline Excellent & $70.1(60.4-79.7)$ & $65.3(55.2-75.4)$ \\
\hline Very good & $45.3(39.5-51.1)$ & $60.8(54.0-67.5)$ \\
\hline Good & $23.6(19.9-27.4)$ & $44.1(39.3-48.8)$ \\
\hline Fair & $13.6 \quad(9.9-17.3)$ & $28.5(22.5-34.4)$ \\
\hline Poor & $12.8(7.6-17.9)^{\mathrm{a}}$ & $18.0(10.5-25.4)^{\mathrm{a}}$ \\
\hline \multicolumn{3}{|l|}{ Functional limitations } \\
\hline No or only a little limitations & $41.0(37.3-44.6)$ & $53.4(49.3-57.5)$ \\
\hline 1-2 limitations & $21.0(15.2-26.9)$ & $42.7(36.2-49.3)$ \\
\hline 3 limitations or more & $7.9(4.7-11.1)^{\mathrm{a}}$ & $24.1(18.0-30.3)$ \\
\hline
\end{tabular}

3 or more. Finally, those with only a mood disorder or only an anxiety disorder were more likely to report high SRMH than those with both a mood and an anxiety disorder. After entering health variables, income was no longer significantly associated with high SRMH.

Self-management behaviours were entered in Model 3. None of these variables were significantly associated with high SRMH. Stress, coping and social support variables were entered in Model 4 (excluding selfmanagement behaviours). When these variables were included in the model, the association between sex and high SRMH became significant, with women being 1.5 times as likely to report high SRMH as men. Age continued to be significant. Health and functioning variables continued to be significant, although having only a mood disorder was no longer significant. All stress, coping and social support variables were associated with reporting high SRMH. Decreasing levels of perceived stress were associated with increasing odds of high SRMH. Those who reported better coping skills or more social support were also more likely to report high SRMH.

\section{Life satisfaction}

Results for LS (Table 3) are broadly similar to those for SRMH. In Model 1, both younger (18-34) and older ages $(65+)$ were associated with higher odds of high LS, as compared to those aged 35 to 49 years. People who were married or living with a common-law spouse were more likely to report high LS as compared to people who were single. There was a graded association with income; the odds of reporting high LS increased with higher income. There were no significant associations with sex, education, immigration status or urban/rural status in the sociodemographic-only model.

When adding health and functioning variables (Model 2), the odds of reporting high LS increased with better self-rated health. Those that reported fewer functional limitations also had higher odds of reporting high LS, as compared to those with three or more limitations. In contrast to the model predicting SRMH, there were no significant differences between those with an anxiety disorder only, mood disorder only or both mood and anxiety disorders. When health and functioning variables were accounted for, most of the 
TABLE 1 (continued)

Percentage of respondents with high self-rated mental health or high life satisfaction by sociodemographic, health and functioning, self-management and stress, coping and social support characteristics, Canada, 2014 SLCDC-MA

\begin{tabular}{|c|c|c|}
\hline \multirow[t]{2}{*}{ Characteristics } & Self-rated mental health & Life satisfaction \\
\hline & $\begin{array}{l}\text { High level } \\
\%(95 \% \mathrm{Cl})\end{array}$ & $\begin{array}{l}\text { High level } \\
\%(95 \% \mathrm{Cl})\end{array}$ \\
\hline \multicolumn{3}{|l|}{ Type of disorder } \\
\hline Both mood and anxiety & $16.4(13.1-19.6)$ & $36.9(31.9-41.9)$ \\
\hline Mood only & $34.7(30.5-38.9)$ & $47.8(43.2-52.4)$ \\
\hline Anxiety only & $44.2(37.9-50.5)$ & $55.0(48.1-62.0)$ \\
\hline \multicolumn{3}{|l|}{ Exercise } \\
\hline Started exercising, continued every day & $30.8(23.7-37.9)$ & $44.7(36.1-53.3)$ \\
\hline Started exercising, continued 4-6X/wk & $43.0(34.5-51.5)$ & $59.7(51.0-68.3)$ \\
\hline $\begin{array}{l}\text { Started exercising, continued } 2-3 \mathrm{X} / \mathrm{wk} \\
\text { or less }\end{array}$ & $29.2(23.5-35.0)$ & $51.8(45.2-58.4)$ \\
\hline Started exercising but stopped & $29.4(23.1-35.8)$ & $40.0(33.1-46.9)$ \\
\hline Never started exercising & $30.2(25.9-34.6)$ & $41.2(36.5-45.8)$ \\
\hline \multicolumn{3}{|l|}{ Adopted good sleep habits after diagnosis } \\
\hline Yes & $30.0(26.9-33.2)$ & $45.2(41.7-48.6)$ \\
\hline No & $34.5(29.5-39.4)$ & $48.7(43.0-54.3)$ \\
\hline \multicolumn{3}{|l|}{ No. of hours of sleep (usual) per night } \\
\hline Less than 6 hours & $20.6(15.5-25.8)$ & $32.4(25.4-39.3)$ \\
\hline 6 hours to less than 9 hours & $34.6(31.2-38.0)$ & $50.2(46.4-54.1)$ \\
\hline 9 hours or more & $30.2(23.7-36.8)$ & $45.0(38.1-51.9)$ \\
\hline \multicolumn{3}{|l|}{ Used meditation to manage condition } \\
\hline Yes & $31.4(27.4-35.4)$ & $46.3(42.0-50.6)$ \\
\hline No & $31.3(27.8-34.8)$ & $46.1(41.9-50.3)$ \\
\hline \multicolumn{3}{|l|}{ Perceived stress } \\
\hline Not at all stressful & $65.3(51.3-79.2)$ & $61.7(48.2-75.2)$ \\
\hline Not very stressful & $46.8(40.8-52.9)$ & $61.4(55.1-67.6)$ \\
\hline A bit stressful & $33.1(29.0-37.2)$ & $49.2(44.4-53.9)$ \\
\hline Quite a bit or extremely stressful & $20.0(16.4-23.6)$ & $35.2(30.4-39.9)$ \\
\hline \multicolumn{3}{|l|}{ Coping } \\
\hline High level of coping & $59.5(53.6-65.5)$ & $61.9(56.0-67.7)$ \\
\hline Low level of coping & $21.8(19.1-24.5)$ & $40.9(37.4-44.4)$ \\
\hline \multicolumn{3}{|l|}{ Perceived social support } \\
\hline High level of social support & $35.5(32.4-38.6)$ & $51.8(48.2-55.3)$ \\
\hline Low level of social support & $14.3(10.6-18.0)$ & $22.8(17.6-28.1)$ \\
\hline
\end{tabular}

Abbreviations: Cl, confidence interval; Q, quintile; SLCDC-MA, Survey on Living with Chronic Diseases in Canada-Mood and Anxiety Disorders Component; $\mathrm{X} / \mathrm{wk}$, times per week.

Notes: Self-rated mental health (SRMH) was considered high if respondents reported very good or excellent SRMH; life satisfaction (LS) was considered high if participants reported a score of 8 or higher on a scale of 0-10.

${ }^{a}$ Interpret these results with caution as they have a coefficient of variation between $16.6 \%$ and $33.3 \%$. income associations became non-significant, except that the odds of reporting high LS continued to be higher in the highest income group as compared to the lowest income groups.

We observed no significant associations between life satisfaction and self-management behaviours when these variables were added to the model (Model 3); however, all stress, coping and social support variables yielded significant associations (Model 4). Those reporting lower levels of life stress had higher odds of reporting high LS, as compared to those with the highest level of life stress. Those who reported better coping skills and more social support had significantly higher odds of reporting high LS than those with low coping skills and low levels of social support. When stress, coping and social support variables were added, women had significantly greater odds of reporting high LS, as compared to men. Marital status and income (highest income group only) continued to be significant in this model.

\section{Discussion}

Overall, one-third of Canadians who reported that they have been diagnosed with a mood disorder and nearly half of Canadians with an anxiety disorder reported very good or excellent SRMH. However, only $16 \%$ of those with both a mood and an anxiety disorder reported very good or excellent SRMH. Levels of LS were also relatively high, with a mean rating of 6.98 for the sample overall, and even higher means for respondents reporting only a mood disorder (7.01) or only an anxiety disorder (7.49). The prevalence of high LS was significantly lower for those with both a mood and an anxiety disorder than it was for those with only one disorder.

Bivariate analyses demonstrated that the prevalence of high SRMH or high LS varied by sociodemographic characteristics, health and functioning and stress, coping and social support. However, of the selfmanagement behaviours, there were only significant differences associated with hours of sleep.

A significantly greater proportion of older adults (aged $65+$ ) reported a high level of SRMH than adults aged 35 to 49 . This relationship persisted in the multivariate models for both SRMH and LS. However, when stress, coping and social support 
TABLE 2

Logistic regression models predicting high self-rated mental health (SRMH) among Canadians aged 18 years and older with mood and/or anxiety disorders

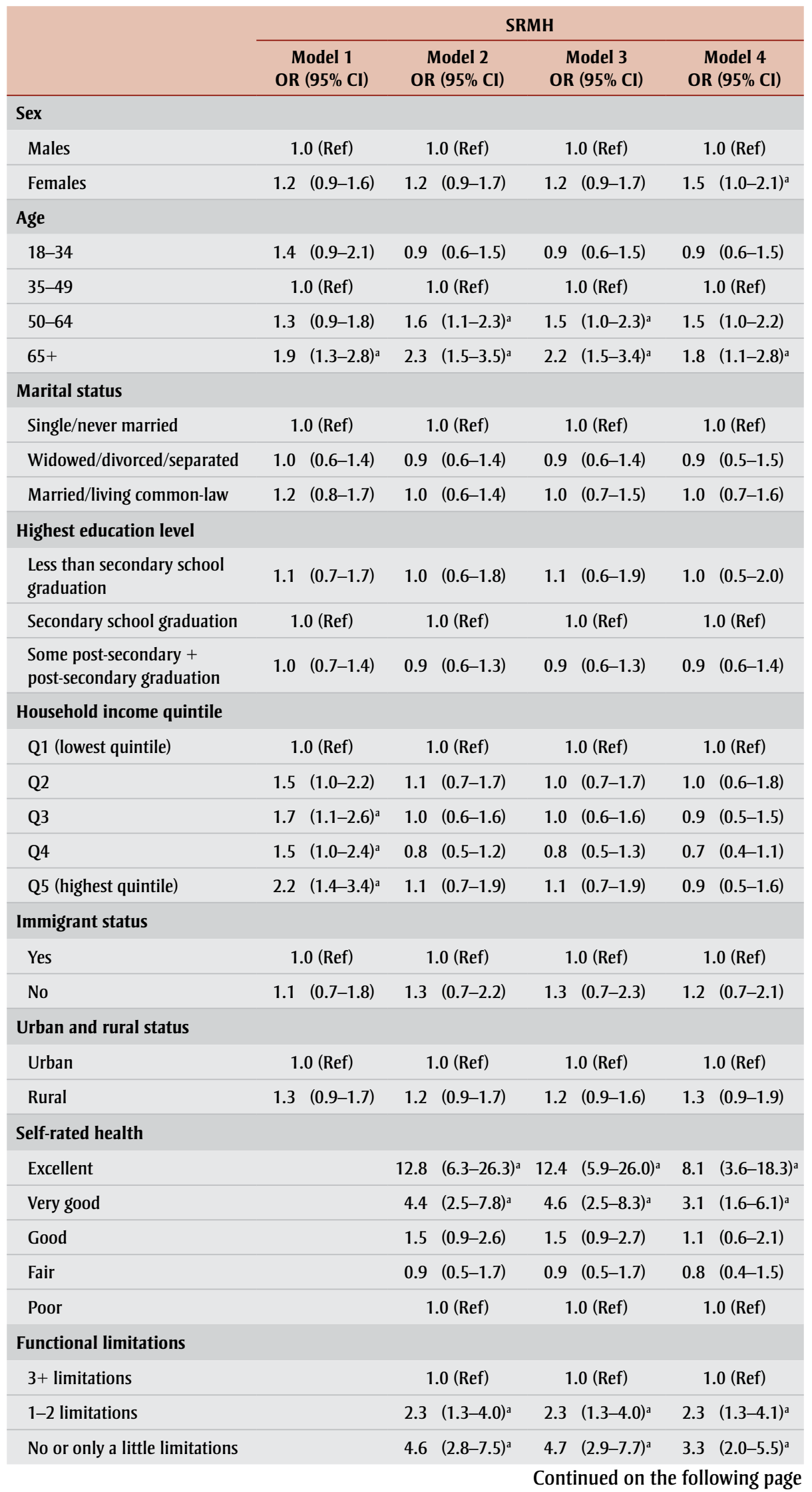

variables were added to the LS model, this relationship was no longer significant. While the literature indicates that there appear to be lower levels of mental health disorders and psychological distress among older adults, ${ }^{33}$ it is interesting to see that even among adults with a mood and/or an anxiety disorder older age is associated with higher levels of well-being. Whether this is an age or cohort effect is an important consideration.

Women were more likely to have high SRMH or LS than men once stress, coping and social support variables were included in the model. Higher income was associated with greater odds of LS and SRMH, which is consistent with studies demonstrating that higher income is associated with higher subjective well-being. ${ }^{34}$ After adding health variables (Model 2), these relationships were attenuated for LS, and were no longer significant for SRMH. Because of the reciprocal relationship between health and income, it is important for future research to investigate this relationship. Education was not associated with higher well-being in this population. It may be that the effects of education are mediated by income and therefore including both in the model resulted in non-significant results for education.

Those who were married or living in common-law relationships had significantly higher odds of reporting high LS than those who were single/never married or widowed/divorced. This is consistent with previous literature indicating that being single, separated, divorced or widowed is associated with poorer mental health outcomes. ${ }^{35}$ There is some literature to suggest that it is not merely having a relationship, but rather the quality of the relationship that is the better predictor of well-being. ${ }^{36}$ The large and significant associations we observed with social support also support this idea.

In contrast to previous findings that have shown the benefits of exercise for improving mood and well-being in people experiencing depression and/or many of the anxiety disorders, ${ }^{8-12}$ in our sample, starting and/or continuing exercise as a selfmanagement behaviour was not associated with significantly higher levels of wellbeing. However, the measure used in our study did not include actual levels of physical activity, and we excluded 
TABLE 2 (continued)

Logistic regression models predicting high self-rated mental health (SRMH) among Canadians aged 18 years and older with mood and/or anxiety disorders

\begin{tabular}{|c|c|c|c|c|}
\hline & \multicolumn{4}{|c|}{ SRMH } \\
\hline & $\begin{array}{c}\text { Model } 1 \\
\text { OR }(95 \% \mathrm{CI})\end{array}$ & $\begin{array}{c}\text { Model } 2 \\
\text { OR }(95 \% \mathrm{CI})\end{array}$ & $\begin{array}{c}\text { Model } 3 \\
\text { OR }(95 \% \mathrm{CI})\end{array}$ & $\begin{array}{c}\text { Model } 4 \\
\text { OR }(95 \% \mathrm{Cl})\end{array}$ \\
\hline \multicolumn{5}{|l|}{ Type of disorder } \\
\hline Both mood and anxiety & & 1.0 (Ref) & 1.0 (Ref) & 1.0 (Ref) \\
\hline Mood only & & $1.7(1.2-2.3)^{\mathrm{a}}$ & $1.7(1.2-2.3)^{\mathrm{a}}$ & $1.4(0.9-1.9)$ \\
\hline Anxiety only & & $2.3(1.5-3.5)^{\mathrm{a}}$ & $2.4(1.6-3.6)^{\mathrm{a}}$ & $2.1(1.3-3.2)$ \\
\hline \multicolumn{5}{|l|}{ Exercise } \\
\hline $\begin{array}{l}\text { Started exercising, continued } \\
\text { every day }\end{array}$ & & & $0.9 \quad(0.5-1.5)$ & \\
\hline $\begin{array}{l}\text { Started exercising, continued } \\
4-6 \mathrm{X} / \mathrm{wk}\end{array}$ & & & $1.1(0.6-1.9)$ & \\
\hline $\begin{array}{l}\text { Started exercising, continued } \\
2-3 \mathrm{X} / \mathrm{wk} \text { or less }\end{array}$ & & & $0.7 \quad(0.4-1.2)$ & \\
\hline Started exercising but stopped & & & 1.0 (Ref) & \\
\hline Haven't started exercising & & & $0.8 \quad(0.5-1.4)$ & \\
\hline \multicolumn{5}{|c|}{ Adopted good sleep habits after diagnosis } \\
\hline Yes & & & $0.9 \quad(0.7-1.3)$ & \\
\hline No & & & 1.0 (Ref) & \\
\hline \multicolumn{5}{|c|}{ No. hours of sleep usually slept per night } \\
\hline Less than 6 hours & & & 1.0 (Ref) & \\
\hline 6 hours to less than 9 hours & & & $1.0 \quad(0.7-1.6)$ & \\
\hline 9 hours or more & & & $1.3 \quad(0.7-2.2)$ & \\
\hline \multicolumn{5}{|c|}{ Used meditation to manage condition } \\
\hline Yes & & & $1.2(0.9-1.7)$ & \\
\hline No & & & 1.0 (Ref) & \\
\hline \multicolumn{5}{|l|}{ Perceived stress } \\
\hline Not at all stressful & & & & $4.3 \quad(1.9-9.8)$ \\
\hline Not very stressful & & & & $2.4(1.6-3.6)$ \\
\hline A bit stressful & & & & $1.7 \quad(1.2-2.4)$ \\
\hline $\begin{array}{l}\text { Quite a bit or extremely } \\
\text { stressful }\end{array}$ & & & & 1.0 (Ref) \\
\hline \multicolumn{5}{|l|}{ Coping } \\
\hline High level of coping & & & & $4.2(3.0-6.0)$ \\
\hline Low level of coping & & & & 1.0 (Ref) \\
\hline \multicolumn{5}{|l|}{ Perceived social support } \\
\hline High level of social support & & & & $1.7(1.1-2.7)$ \\
\hline Low level of social support & & & & 1.0 (Ref) \\
\hline
\end{tabular}

Abbreviations: $\mathrm{Cl}$, confidence interval; OR, odds ratio; Q, quintile; Ref, reference group; SRMH, self-rated mental health; $\mathrm{X} / \mathrm{wk}$, times per week.

Notes: Self-rated mental health (SRMH) was considered high if respondents reported "very good" or "excellent" SRMH.

Model 1 is the initial model including only sociodemographic variables. Model 2 includes sociodemographic and health and functioning variables. Model 3 includes these variables as well as self-management behaviours. Model 4 includes sociodemographic, health and functioning, and stress, coping and social support variables, but not self-management variables.

a Statistically significant at $p<.05$. respondents who reported that they were already exercising. Future research should rely on stronger measures of physical activity, including levels of physical activity, as well as reasons for physical activity. Respondents who slept from 6 to less than 9 hours per night, as opposed to 6 hours or less, reported higher levels of wellbeing, but this relationship did not persist in the logistic regression models.

Perhaps surprisingly, given its current popularity in mental health treatment, meditation was not a significant predictor of well-being in our sample. It is difficult to speculate why, given that we do not have specific details as to the type of meditation, frequency and duration of practice and/or formal training that participants had when engaging in meditative practices. Our results, however, are not inconsistent with the literature, which has found mixed results on the impact of meditation on well-being. ${ }^{18}$ Our study describes a nationally representative sample of people experiencing mood and/or anxiety disorders who are engaging in what they consider to be meditation in a normal life setting, which is an important contribution to the literature on this topic. However, more detailed research is needed before drawing any conclusions.

In the multivariate logistic regression models, lower stress, higher levels of social support and higher levels of coping skills were all significantly associated with high odds of well-being. Given that successful coping often includes strategies that are consistent with skills promoted in treatment, ${ }^{19}$ one would expect healthy coping strategies to promote well-being. Likewise, those who reported a high level of perceived social support were more likely to report high SRMH and LS, which is consistent with the literature on wellbeing among those with mood and anxiety disorders. ${ }^{25,26}$

\section{Strengths and limitations}

This study examines well-being in a representative sample of the Canadian household population living with mood and/or anxiety disorders. It provides a useful description of the prevalence of well-being and its relationship to self-management behaviours and stress, coping and social support in this population. This sample differs from most other studies of this topic, which tend to focus on small, 
TABLE 3

Logistic regression models predicting high life satisfaction among Canadians aged 18 years and older with mood and/or anxiety disorders

\begin{tabular}{|c|c|c|c|c|}
\hline & \multicolumn{4}{|c|}{ LS } \\
\hline & Model 1 & Model 2 & Model 3 & Model 4 \\
\hline & OR $(95 \% \mathrm{Cl})$ & OR $(95 \% \mathrm{Cl})$ & OR $(95 \% \mathrm{CI})$ & OR $(95 \% \mathrm{Cl})$ \\
\hline \multicolumn{5}{|l|}{ Sex } \\
\hline Males & 1.0 (Ref) & 1.0 (Ref) & 1.0 (Ref) & 1.0 (Ref) \\
\hline Females & $1.3(1.0-1.8)$ & $1.3(1.0-1.8)$ & $1.3(1.0-1.8)$ & $1.4(1.0-2.0)^{\mathrm{a}}$ \\
\hline \multicolumn{5}{|l|}{ Age } \\
\hline $18-34$ & $1.8 \quad(1.2-2.9)^{\mathrm{a}}$ & $1.6 \quad(1.0-2.5)$ & $1.5 \quad(0.9-2.5)$ & $1.6(1.0-2.6)$ \\
\hline $35-49$ & 1.0 (Ref) & 1.0 (Ref) & 1.0 (Ref) & 1.0 (Ref) \\
\hline $50-64$ & $1.0 \quad(0.7-1.5)$ & $1.2 \quad(0.8-1.7)$ & $1.1 \quad(0.8-1.7)$ & $1.1 \quad(0.7-1.6)$ \\
\hline $65+$ & $1.6(1.1-2.3)^{\mathrm{a}}$ & $1.7(1.1-2.6)^{\mathrm{a}}$ & $1.7(1.1-2.6)^{\mathrm{a}}$ & $1.4 \quad(0.9-2.1)$ \\
\hline
\end{tabular}

\section{Marital status}

Single/never married

1.0 (Ref)

1.0 (Ref)

1.0 (Ref)

1.0 (Ref)

Widowed/divorced/separated

Married/living common-law

$1.2 \quad(0.8-1.9)$

$1.2(0.8-1.9)$

$1.2(0.8-1.9)$

$1.3(0.8-2.0)$

Highest education level

Less than secondary school graduation

$1.8(1.2-2.7)^{\mathrm{a}}$

$1.7(1.1-2.5)^{\mathrm{a}}$

$1.7(1.1-2.6)^{\mathrm{a}}$

$1.8(1.2-2.8)^{\mathrm{a}}$

Secondary school graduation

$1.2 \quad(0.7-2.1)$

$1.2(0.7-2.1)$

$1.2(0.7-2.1)$

$1.5 \quad(0.8-2.6)$

Some post-secondary + post-secondary graduation

1.0 (Ref)

1.0 (Ref)

1.0 (Ref)

1.0 (Ref)

Household income quintile

Q1 (lowest quintile)

$0.9 \quad(0.7-1.3)$

$0.9 \quad(0.6-1.3)$

$0.9 \quad(0.6-1.2)$

$0.9 \quad(0.6-1.3)$

Q2

Q3

\section{0 (Ref)}

1.0 (Ref)

1.0 (Ref)

1.0 (Ref)

$1.1 \quad(0.7-1.6)$

$0.8 \quad(0.5-1.3)$

$0.8 \quad(0.5-1.3)$

$0.8 \quad(0.5-1.3)$

$1.8(1.2-2.7)^{\mathrm{a}}$

$1.2 \quad(0.7-1.9)$

$1.2 \quad(0.7-1.9)$

$1.1 \quad(0.7-1.9)$

Q4

Q5 (highest quintile)

$2.2(1.5-3.4)^{\mathrm{a}}$

$1.5(1.0-2.4)$

$1.5 \quad(0.9-2.4)$

$1.5 \quad(0.9-2.4)$

$3.1 \quad(1.9-4.9)^{\mathrm{a}} \quad 2.0 \quad(1.2-3.4)^{\mathrm{a}}$

$2.0(1.2-3.3)^{\mathrm{a}}$

$1.9(1.1-3.4)^{\mathrm{a}}$

Immigrant status

Yes

$$
1.0 \text { (Ref) }
$$

1.0 (Ref)

$1.0 \quad(0.6-1.7)$

$1.0 \quad(0.6-1.8)$

1.0 (Ref)

1.0 (Ref)

No

$$
\begin{gathered}
1.0 \text { (Ref) } \\
1.2 \quad(0.9-1.6)
\end{gathered}
$$

1.0 (Ref)

$1.2(0.9-1.6)$

1.0 (Ref)

1.0 (Ref)

\begin{tabular}{|c|c|c|c|}
\hline Excellent & $5.4(2.5-11.7)^{\mathrm{a}}$ & $4.7(2.1-10.6)^{\mathrm{a}}$ & $3.2(1.4-7.4)^{\mathrm{a}}$ \\
\hline Very good & $4.7 \quad(2.5-9.1)^{\mathrm{a}}$ & $4.3(2.2-8.3)^{\mathrm{a}}$ & $3.2(1.6-6.4)^{\mathrm{a}}$ \\
\hline Good & $2.6(1.4-4.7)^{\mathrm{a}}$ & $2.4(1.3-4.5)^{\mathrm{a}}$ & $1.9(1.0-3.6)$ \\
\hline Fair & $1.7 \quad(0.9-3.2)$ & $1.6(0.9-3.0)$ & $1.4 \quad(0.7-2.7)$ \\
\hline Poor & 1.0 (Ref) & 1.0 (Ref) & 1.0 (Ref) \\
\hline
\end{tabular}

Rural

Self-rated health

Functional limitations

3+ limitations

1.0 (Ref)

1.0 (Ref)

1.0 (Ref)

1-2 limitations

$1.9(1.2-3.0)^{\mathrm{a}}$

$2.0(1.2-3.1)$

$1.8(1.1-3.0)^{\mathrm{a}}$

No or only a little limitations
$2.3 \quad(1.4-3.6)^{\mathrm{a}} \quad 2.2 \quad(1.4-3.6)^{\mathrm{a}} \quad 1.6 \quad(1.1-3.0)$

Continued on the following page clinical samples. Furthermore, most studies on mental health examine mental disorder and dysfunction; understanding correlates of positive mental health among people living with mental disorders can provide important insight into recovery, and the results of this study demonstrate that it is possible to achieve high levels of well-being even while living with a mental illness.

However, several significant limitations must be acknowledged. We do not have accurate information about the current status of the respondents' mood and/or anxiety disorder. When examining wellbeing, it would be ideal to understand which respondents were currently experiencing symptoms, and which respondents had had a previous episode that had resolved. While we have used functional limitations associated with the mood and/ or anxiety disorder as a proxy for current disorder status, this is an imperfect measure.

Problems with sleep, including sleeping more or less than usual, are part of the diagnostic criteria for MDD. ${ }^{13}$ It is possible that the differences in well-being we observed according to sleep time in univariate analyses are a function of experiencing a current episode of MDD.

The cross-sectional nature of this survey does not allow us to examine temporal sequencing. This makes it impossible to infer whether well-being influences stress, coping and social support attributes or whether these factors affect well-being. Likely, both are true to some extent. Longitudinal and experimental study designs can help address these questions. However, understanding these relationships in a large, population-based sample is also useful, and can test the generalizability of findings from smaller studies.

Finally, while there is a risk that response bias accounts for some of the observed relationships, the complete absence of significant relationships between selfmanagement behaviours and well-being suggest that this is not the case (i.e. if significant findings were due only to a response bias, then the relationship between self-management behaviours and well-being should have been positive and significant as well). 
TABLE 3 (continued)

Logistic regression models predicting high life satisfaction among Canadians aged 18 years and older with mood and/or anxiety disorders

\begin{tabular}{|c|c|c|c|c|}
\hline & \multicolumn{4}{|c|}{ LS } \\
\hline & $\begin{array}{c}\text { Model } 1 \\
\text { OR }(95 \% \mathrm{Cl})\end{array}$ & $\begin{array}{c}\text { Model } 2 \\
\text { OR }(95 \% \mathrm{Cl})\end{array}$ & $\begin{array}{c}\text { Model } 3 \\
\text { OR }(95 \% \mathrm{CI})\end{array}$ & $\begin{array}{c}\text { Model } 4 \\
\text { OR }(95 \% \mathrm{CI})\end{array}$ \\
\hline \multicolumn{5}{|l|}{ Type of disorder } \\
\hline Both mood and anxiety & & 1.0 (Ref) & 1.0 (Ref) & 1.0 (Ref) \\
\hline Mood only & & $1.1 \quad(0.8-1.6)$ & $1.2(0.8-1.6)$ & $1.0 \quad(0.7-1.4)$ \\
\hline Anxiety only & & $1.3(0.9-1.9)$ & $1.3 \quad(0.9-1.9)$ & $1.1 \quad(0.8-1.7)$ \\
\hline \multicolumn{5}{|l|}{ Exercise to manage condition } \\
\hline $\begin{array}{l}\text { Started exercising, continued } \\
\text { every day }\end{array}$ & & & $1.5(0.8-2.6)$ & \\
\hline $\begin{array}{l}\text { Started exercising, continued } \\
4-6 \mathrm{X} / \mathrm{wk}\end{array}$ & & & $1.6 \quad(0.9-2.7)$ & \\
\hline $\begin{array}{l}\text { Started exercising, continued } \\
2-3 \mathrm{X} / \mathrm{wk} \text { or less }\end{array}$ & & & $1.3 \quad(0.8-2.1)$ & \\
\hline Started exercising but stopped & & & 1.0 (Ref) & \\
\hline Haven't started exercising & & & $1.0 \quad(0.6-1.5)$ & \\
\hline \multicolumn{5}{|l|}{$\begin{array}{l}\text { Adopted good sleep habits } \\
\text { after diagnosis }\end{array}$} \\
\hline Yes & & & $0.8 \quad(0.6-1.1)$ & \\
\hline No & & & 1.0 (Ref) & \\
\hline \multicolumn{5}{|l|}{$\begin{array}{l}\text { No. of hours of sleep (usual) } \\
\text { per night }\end{array}$} \\
\hline Less than 6 hours & & & 1.0 (Ref) & \\
\hline 6 hours to less than 9 hours & & & $1.2(0.8-1.8)$ & \\
\hline 9 hours or more & & & $1.5 \quad(0.9-2.3)$ & \\
\hline \multicolumn{5}{|l|}{$\begin{array}{l}\text { Used meditation to manage } \\
\text { condition }\end{array}$} \\
\hline Yes & & & $1.0 \quad(0.7-1.4)$ & \\
\hline No & & & 1.0 (Ref) & \\
\hline \multicolumn{5}{|l|}{ Perceived stress } \\
\hline Not at all stressful & & & & $1.8 \quad(0.9-3.7)$ \\
\hline Not very stressful & & & & $2.2(1.5-3.4)^{a}$ \\
\hline A bit stressful & & & & $1.5(1.1-2.1)^{\mathrm{a}}$ \\
\hline $\begin{array}{l}\text { Quite a bit or extremely } \\
\text { stressful }\end{array}$ & & & & 1.0 (Ref) \\
\hline \multicolumn{5}{|l|}{ Coping } \\
\hline High level of coping & & & & $1.9(1.4-2.7)^{\mathrm{a}}$ \\
\hline Low level of coping & & & & 1.0 (Ref) \\
\hline \multicolumn{5}{|l|}{ Perceived social support } \\
\hline High level of social support & & & & $1.9(1.3-2.8)^{\mathrm{a}}$ \\
\hline Low level of social support & & & & 1.0 (Ref) \\
\hline
\end{tabular}

Abbreviations: $\mathrm{Cl}$, confidence interval; $\mathrm{LS}$, life satisfaction; $\mathrm{OR}$, odds ratio; Ref, reference group; $\mathrm{Q}$, quintile; $\mathrm{X} / \mathrm{wk}$, times per week. Notes: Life satisfaction was considered high if participants reported a score of 8 or higher on a scale of 0-10.

Model 1 is the initial model including only sociodemographic variables. Model 2 includes sociodemographic and health and functioning variables. Model 3 includes these variables as well as self-management behaviours. Model 4 includes sociodemographic, health and functioning, and stress, coping and social support variables, but not self-management variables.

${ }^{\text {a }}$ Statistically significant at $p<.05$.

\section{Conclusion}

When we included sociodemographic characteristics, health and functioning, self-management behaviours and stress, coping and social support in logistic regression models, we found that none of the self-management behaviours were significantly associated with high levels of well-being. Stress, coping and social support, however, were. This finding suggests that healthy coping strategies and strong perceived social support may be important for Canadians with mood and/or anxiety disorders to achieve well-being in the presence of their disorder.

Helping Canadians with mood and/or anxiety disorders to access or build strong social support networks and to develop effective coping strategies are likely important goals, both for mental health professionals and for Canadians experiencing these disorders. Furthermore, a continued focus on the social determinants of well-being, including income, is warranted.

\section{Conflict of interest}

None.

\section{References}

1. Mental Health Commission of Canada. Changing directions, changing lives: the mental health strategy for Canada. Calgary (AB): Mental Health Commission of Canada; 2012.

2. Ryan RM, Deci EL. On happiness and human potentials: a review of research on hedonic and eudaimonic wellbeing. Annu Rev Psychol. 2001 Feb; 52(1):141-66.

3. Lakaski C, Trottier M. Developing an operational definition of positive mental health: final report based on consultation and workshop, February 26-27, 2009, Ottawa, Ontario. Public Health Agency of Canada unpublished report.

4. World Health Organization. Mental health: a state of well-being [Internet]. Geneva: World Health Organization [updated 2014 Aug 1; cited 2016-Jun 8]. Available from: http://www.who .int/features/factfiles/mental_health /en/ 
5. WHOQOL group. The World Health Organization quality of life assessment (WHOQOL): position paper from the World Health Organization. Soc Sci \& Med. 1995 Nov 30;41(10): 1403-9.

6. Goldberg JF, Harrow M. Subjective life satisfaction and objective functional outcome in bipolar and unipolar mood disorders: a longitudinal analysis. J Affective Disord. 2005;89(1-3): 79-89.

7. Sarris J, O'Neil A, Coulson CE, Schweitzer I, Berk M. Lifestyle medicine for depression. BMC Psychiatry. 2014 Apr 10;14:107.

8. Ströhle A. Physical activity, exercise, depression and anxiety disorders. J Neural Transm. 2009 Jun;116(6): 777-84.

9. Bartholomew JB, Morrison D, Ciccolo JT. Effects of acute exercise on mood and well-being in patients with major depressive disorder. Med Sci Sports Exerc. 2005 Dec 1;37(12):2032-7.

10. Galper DI, Trivedi MH, Barlow CE, Dunn AL, Kampert JB. Inverse association between physical inactivity and mental health in men and women. Med Sci Sports Exerc. 2006 Jan 1;38(1):173-8.

11. Asmundson GJG, Fetzner MG, DeBoer LB, Powers MB, Otto MW, Smits JAJ. Let's get physical: a contemporary review of the anxiolytic effects of exercise for anxiety and its disorders. Depress Anxiety. 2013 Apr;30(4):362-73.

12. Knapen J, Sommerijns E, Vancampfort $\mathrm{D}$, et al. State anxiety and subjective well-being responses to acute bouts of aerobic exercise in patients with depressive and anxiety disorders. Br J Sports Med. 2009;43(10):756-9.

13. American Psychiatric Association. Diagnostic and statistical manual of mental disorders. 5th ed. Washington (DC): American Psychiatric Publications; 2013.

14. Hamilton NA, Nelson CA, Stevens N, Kitzman H. Sleep and psychological well-being. Soc Indic Res. 2007 May 1;82(1):147-63.
15. Ryff CD. Psychological well-being in adult life. Curr Dir Psychol Sci. 1995 Aug 1;4(4):99-104.

16. Peth J, Regen F, Bajbouj M, Heuser I, Anghelescu I, Hornung OP. The influence of daytime napping versus controlled activity on the subjective well-being of patients with major depression. Psychiatry Res. 2012 Dec; 200(2-3):368-73.

17. Leung NT, Lo MM, Lee TM. Potential therapeutic effects of meditation for treating affective dysregulation. Evid Based Complement Alternat Med. 2014;2014:1-7.

18. Galante J, Galante I, Bekkers M, Gallacher J. Effect of kindness-based meditation on health and well-being: a systematic review and meta-analysis. J Consult Clin Psychol. 2014; 82(6):1101-14

19. Suto M, Murray G, Hale S, Amari E, Michalak EE. What works for people with bipolar disorder? Tips from the experts. J Affect Disord. 2010 Jul 31;124(1):76-84.

20. Brown GW, Harris TO, editors. Life events and illness. New York: Guilford Press; 1989.

21. Brown GW, Andrews $\mathrm{B}$, Harris $\mathrm{T}$, Adler Z, Bridge L. Social support, self-esteem and depression. Psychol Med. 1986 Nov 1;16(04):813-31.

22. Schiffrin HH, Nelson SK. Stressed and happy? Investigating the relationship between happiness and perceived stress. J Happiness Stud. 2010 Mar 1;11(1):33-9.

23. Folkman S, Moskowitz JT. Coping: pitfalls and promise. Annu Rev Psychol. 2004;55:745-74.

24. Sin NL, Lyubomirsky S. Enhancing well-being and alleviating depressive symptoms with positive psychology interventions: a practice-friendly metaanalysis. J Clin Psychol. 2009 May 1; 65(5):467-87.

25. Kuehner C, Buerger C. Determinants of subjective quality of life in depressed patients: the role of selfesteem, response styles, and social support. J Affect Disord. 2005 Jun 30;86(2):205-13.
26. Panayiotou G, Karekla M. Perceived social support helps, but does not buffer the negative impact of anxiety disorders on quality of life and perceived stress. Soc Psychiatry Psychiatr Epidemiol. 2013 Feb 1;48(2):283-94.

27. O’Donnell S, Cheung R, Bennett K, Lagacé C. The 2014 Survey on Living with Chronic Diseases in Canada on Mood and Anxiety Disorders: a methodological overview. Health Promot Chronic Dis Prev Can. 2016; 36(12):275-88.

28. Statistics Canada. Perceived mental health by age group and sex [Internet]. Ottawa (ON): Statistics Canada; [updated: 2016 Mar 06; cited 2016 Jun 08]. Available from http:// www.statcan.gc.ca/tables-tableaux /sum-som/101/cst01/health110d-eng .htm

29. Orpana H, Vachon J, Dykxhoorn J, McRae L, Jayaraman G. Monitoring positive mental health and its determinants in Canada: the development of the Positive Mental Health Surveillance Indicator Framework. Health Promot Chronic Dis Prev Can. 2016 Jan;36(1):1-10.

30. Diener E. Subjective well-being: the science of happiness and a proposal for a national index. Am Psychol. 2000;55(1):34-43.

31. House JS, Umberson D, Landis KR. Structures and processes of social support. Ann Rev Sociol. 1988 Aug; 14:293-318.

32. Cutrona CE, Russell DW. The provisions of social support and adaptation to stress. Advances Personal Relation. 1987;1:37-67.

33. Jeste DV, Blazer DG, First M. Agingrelated diagnostic variations: need for diagnostic criteria appropriate for elderly psychiatric patients. Biol Psychiatry. 2005 Aug 15;58(4): 265-71.

34. Diener E, Tay L, Oishi S. Rising income and the subjective well-being of nations. J Pers Soc Psychol. 2013 Feb;104(2):267-76. 
35. Lindström M, Rosvall M. Marital status, social capital, economic stress, and mental health: a populationbased study. Soc Sci J. 2012;49: 339-42.

36. Leach LS, Butterworth P, Olesen SC, Mackinnon A. Relationship quality and levels of depression and anxiety in a large population-based survey. Soc Psychiatry Psychiatr Epidemiol. 2013 Mar;48(3):417-25. 